\title{
Qualidade da governança da saúde em Portugal: uma avaliação ao período de intervenção da Troika
}

\author{
The quality of health governance in Portugal: \\ an evaluation of the Troika's intervention period
}

Ricardo Ramos Pinto (https://orcid.org/0000-0001-8347-8293) ${ }^{1}$

Maria Helena Monteiro (https://orcid.org/0000-0002-3782-9707) ${ }^{1}$

Manuel Meirinho Martins (https://orcid.org/0000-0002-7545-271X) ${ }^{1}$

Elisabete Reis de Carvalho (https://orcid.org/0000-0002-5323-3700) ${ }^{1}$

${ }^{1}$ Centro de Administração

e Políticas Públicas, Instituto

Superior de Ciências Sociais

e Políticas, Universidade

de Lisboa. Rua Almerindo

Lessa 1300-663. Lisboa

Portugal.

rrp@iscsp.ulisboa.pt

\begin{abstract}
This study aims to evaluate the quality of the Portuguese Government's action in the health sector during Troika's intervention period (2011-2015), taking as criterion the concern with the application of Good Governance principles, in terms of degree and diversity. The intention is to understand the extent to which the public action promoted by the Ministry of Health has developed seeking to contribute to the strengthening of Good Governance practices. Fifty measures of the Ministry of Health, distributed by nine intervention areas, were analyzed, based on documental analysis, supported on the law and on other official documents. The principles of Good Governance that demonstrate a more transversal concern are clearly that of "transparency" and of "effectiveness/efficiency", present in eight of the nine intervention areas. The concern with "orientation to consensus" is essentially present in the measures classified as Agreements, "independence" in the Ethics area, the "strengthening of the rule of Law" in the Control area and "equity/inclusion" in the area of the Citizen in the Centre of the NHS.
\end{abstract}

Key words Good governance, Health, Portugal, Troika
Resumo Este estudo tem como objetivo avaliar a qualidade da ação do Governo Português no sector da saúde, no período de intervenção da Troika (2011-2015), tomando como critério a preocupação com a aplicação dos princípios de Boa Governança, em termos de grau e diversidade. Pretende-se perceber em que medida a ação pública promovida pelo Ministério da Saúde se desenvolveu procurando contribuir para o fortalecimento das práticas de Boa Governança. Com base em análise documental, suportada nos diplomas legais e em outros documentos oficiais, foram analisadas 50 medidas de ação do Ministério da Saúde, que se distribuem por nove áreas de intervenção. Os princípios de Boa Governança que representam uma preocupação mais transversal são claramente o da "transparência" e o da "eficácial eficiência", presentes em oito das nove áreas de intervenção. A preocupação com a "orientação para consensos" está essencialmente presente nas medidas tipificadas como Acordos, a "independência" na área Ética, o "reforço do Estado de direito" na área Controlo e a "equidade/inclusão" na área Cidadão no Centro do SNS.

Palavras-chave Boa Governança, Saúde, Portugal, Troika 


\section{Introdução}

No início de 2011, Portugal, numa situação de grande fragilidade financeira, viu-se obrigado a solicitar apoio ao Fundo Monetário Internacional (FMI), à Comissão Europeia e ao Banco Central Europeu (BCE), tendo este conjunto de entidades financiadoras ficado vulgarmente conhecido por Troika. O Memorando de Entendimento (MoU - Memorandum of Understanding $)^{1}$, assinado em 17 de maio de 2011, impunha diversas reformas estruturais que, no sector da saúde, implicaram intervenções em três áreas prioritárias: a) foco na eficiência e eficácia do sistema de saúde; b) controlo de despesa e uso mais racional de recursos; c) redução de custos nos hospitais.

De acordo com declarações do Presidente do Conselho Diretivo da Entidade Reguladora da Saúde ${ }^{2}$, no $M o U$ estava prevista uma redução da despesa pública com medicamentos de $1,25 \%$ do PIB até o final de 2012 (cerca de 516 milhões de euros) e de cerca de 1\% do PIB em 2013 (aproximadamente 431 milhões de euros). A aquisição de meios complementares de diagnóstico e terapêutica a privados deveria sofrer um decréscimo de $10 \%$ em 2011 e de mais $10 \%$ em 2012, devendo ainda ser reforçada a concorrência entre prestadores privados e estabelecida a revisão periódica dos preços pagos aos mesmos. No $\mathrm{MoU}$, constava ainda a redução, em um terço, dos custos com o transporte de doentes.

No que refere ao nível hospitalar, apontava-se para um decréscimo, nos custos operacionais, de 100 milhões de euros em 2011 e de outros 100 milhões em 2012, sabendo-se que cerca de 50\% dos custos estão afetos a despesas com pessoal. Nestes montantes não estavam incluídos os valores das dívidas a fornecedores.

$\mathrm{O} M o U$ estipulava a criação de um calendário para liquidação de todos os pagamentos em atraso (superior a 90 dias) e a introdução de procedimentos de controlo padronizados para prevenir o reaparecimento destas situações. No final de 2010, o prazo médio dos pagamentos a fornecedores era de 78 dias para os hospitais do sector público administrativo e de 212 dias para os hospitais do sector público empresarial.

Relativamente ao orçamento dos subsistemas públicos, o $M o U$ determinava uma redução de $30 \%$ em 2012 e de mais $20 \%$ em 2013. Estabelecia ainda que, em 2016, os subsistemas teriam de ser autofinanciados.

O MoU previa ainda a revisão das categorias de isenção de taxas moderadoras, diferenciando positivamente os cuidados de saúde primários, através de taxas mais baixas, face às consultas de especialidade e aos episódios de urgência, e indexando-as automaticamente à inflação. Indicava, ainda, a redução em dois terços das deduções fiscais de despesas com saúde.

A reorganização e racionalização da rede hospitalar era uma das medidas previstas no $M o U$, com vista a uma redução adicional nos custos operacionais de, pelo menos, 5\%, em 2013, através da especialização, da concentração de serviços e da gestão conjunta de unidades. Previa, também, uma utilização mais eficiente das profissões da saúde, sobretudo no que toca à carreira de enfermagem, e a adoção, para todo o pessoal, de um controlo mais rigoroso das horas de trabalho, de modo a reduzir em $10 \%$, pelo menos, as despesas com horas extraordinárias em $2012 \mathrm{e}$ mais 10\% em 2013.

É neste contexto de fortes restrições orçamentais e de grandes constrangimentos externos, impostos pelas entidades financiadoras através das metas estabelecidas no $M o U$, que se desenvolve a ação do XIX Governo Constitucional. O impacto significativo que se verificou no sector da saúde, torna, no nosso entender, relevante a análise da ação governativa no que diz respeito à preocupação com o fortalecimento de práticas (princípios) de Boa Governança neste sector fundamental para a sociedade. Assim, este estudo procurará dar resposta à questão: será que a ação do Governo de Portugal no setor da saúde entre 2011 e 2015 (período de intervenção da Troika), evidencia uma preocupação com a aplicação dos princípios de Boa Governança? O objetivo a prosseguir é avaliar o contributo da ação pública promovida pelo Ministério da Saúde para o fortalecimento das práticas de Boa Governança, atendendo aos seus princípios, em grau e diversidade.

\section{Fundamentos teóricos}

A globalização transfigurou o palco de ação pública. Os Estados têm de atender a problemas complexos e frequentemente difusos, num espaço que já não se confina às fronteiras que tradicionalmente delimitavam a sua soberania. Há consciência de níveis de interdependência crescentes na procura de soluções para problemas partilhados: entre os Estados e as entidades supra e infra-estaduais, entre o público e o privado, entre o centro e a periferia.

A governança, mais do que uma expressão da moda, é o reconhecimento de que as últimas décadas trouxeram transformações no modo como 
a governação se desenrola, impulsionadas por alterações no contexto em que os Estados atuam.

A governança não se plasma num paradigma coeso e consensual ${ }^{3}$. É o produto do assumir de uma realidade em evolução, que traz mudanças ao exercício do papel do Estado e à sua interação com a sociedade civil. Não é igualmente um processo de transformação uniformizadora, uma vez que as instituições, em cada país, acabam por adotar as estruturas e mecanismos de governação que melhor se adequam às suas escolhas, crenças e tradições. Daqui decorre a inexistência de exercícios de reforma iguais. Na prática, os decisores selecionam as ideias-base, os valores, os objetivos e as medidas que encaram como mais próximos das suas intenções, bem como das tradições políticas e culturais das suas populações e territórios, ainda que essa seleção tenha por fonte doutrinas de reforma divulgadas por instâncias internacionais, bem como pelos meios académicos e profissionais da Administração Pública.

As últimas quatro décadas foram marcadas essencialmente por duas doutrinas de reforma - a Nova Gestão Pública (NGP) e a Governança Pública - que se contrapõem ao paradigma de governação dominante ao longo de quase um século: o modelo burocrático, também denominado de profissional weberiano. Na primeira metade dessas quatro décadas, as práticas de inovação encontraram a sua inspiração na NGP, contudo os últimos vinte anos têm conduzido ao triunfo da governança, um conceito mágico, na classificação de Pollitt e Hupe ${ }^{4}$, por ser amplo e ambíguo, moderno e progressista, consensual e amplamente usado pelas comunidades pertinentes.

A palavra governança tem a sua origem etimológica no grego kybernan que teve tradução para o latim gubernare, significando pilotar, orientar ou dirigir ${ }^{5,6}$. Em voga, tem vindo a ser usada em múltiplos sentidos e contextos, o que difuculta uma definição precisa. Contudo podemos encontrar algumas aproximações à sua delimitação.

Um dos textos de referência sobre governança é o de Rhodes ${ }^{7}$ que, em meados dos anos 90, elencou seis usos comuns para governança: estado mínimo, governança corporativa (corporate governance), nova gestão pública, boa governança (good governance), sistema sócio-cibernético e, finalmente, redes auto-organizadas. Enquanto a governança como estado mínimo tem vindo a sofrer menor adesão, à medida que aumenta a consciência da necessidade de o Estado assumir o papel de regulador do sistema ${ }^{8}$, os outros sentidos continuam a marcar as agendas de reforma ${ }^{8}$.
Neste artigo, destaca-se o conceito de Governança como Boa Governança, isto é, procurar que a governação vá ao encontro das necessidades da sociedade, fazendo bom uso dos recursos públicos e respeitando um conjunto de valores como os de justiça, equidade, imparcialidade, legalidade, legitimidade e transparência.

Em síntese, podemos afirmar que a Governança, à semelhança da NGP, pode ser encarada como a resposta à complexidade crescente da sociedade e à dificuldade que o Estado social clássico parece demonstrar em lidar com essa mesma complexidade 9 . Visa redefinir as estruturas, processos e papéis do sector público, para que a Administração Pública seja um catalisador da governança democrática, indo para além da procura de uma maior eficiência, da redução dos custos, e da melhoria da qualidade da prestação de serviços públicos, que estão na base da NGP. Através do prisma da governança de redes e do foco na dimensão interorganizacional, implícita no processo de políticas públicas e na prestação de serviços públicos, os instrumentos a usar reforçam a coordenação dos diferentes atores envolvidos, fazendo uso do seu conhecimento para melhorar a qualidade na prestação de serviços e na formação e implementação de políticas públicas, bem como para aumentar a legitimidade das decisões tomadas, através de processos de cocriação, co-produção e co-responsabilização.

$\mathrm{O}$ atual contexto de governação é o resultado da influência do paradigma da Governança Pública, em acumulação com a perspetiva gestionária da NGP, tendo por base a herança virtuosa do modelo weberiano. Se encararmos os paradigmas de reforma como fazendo parte de um continuum feito de justaposições, em que, de acordo com o contexto, há uma presença simultânea, ainda que em proporções variáveis, dos diferentes paradigmas, tenderemos a compreender a necessidade de a boa governança do sistema saber lidar com a hibridez da prática administrativa e, consequentemente, com os legados dos paradigmas precedentes.

\section{Procedimentos metodológicos}

A avaliação da qualidade da governança tem duas orientações de análise possíveis, que embora complementares, correspondem a abordagens claramente distintas. A primeira e mais frequente, é a avaliação da evolução dos resultados (outcomes). A segunda e menos comum, corresponde à avaliação da adoção e aplicação por parte dos stakeholders 
dos princípios da Boa Governança no desenho e implementação de políticas públicas ${ }^{10}$.

No presente estudo a opção foi pela segunda abordagem, procurando-se avaliar tanto a qualidade da governança na Saúde, no período de intervenção da Troika (2011-2015), quanto a ação pública promovida pelo Ministério da Saúde, o que espelha um compromisso com o fortalecimento das práticas de Boa Governança, patente na preocupação com a promoção dos seus princípios, considerados em termos de grau e diversidade. Assim, procurou-se dar resposta à seguinte questão: Será que a ação do Governo de Portugal no sector da saúde entre 2011 e 2015 (período de intervenção da Troika), evidencia uma preocupação com a aplicação dos princípios de Boa Governança? Pretende-se perceber se é possível identificar na ação pública promovida pelo Ministério da Saúde uma preocupação com a qualidade da governação, materializada na adoção e promoção dos princípios da Boa Governança atendidos na pesquisa realizada. A questão central enunciada anteriormente foi decomposta em quatro questões de investigação a que o estudo procurou dar resposta:

Quais os princípios de Boa Governança que é possível identificar na ação pública do Ministério da Saúde?

Qual o grau de incidência global da preocupação com a promoção de cada um dos princípios de Boa Governança, patente na ação pública do Ministério da Saúde?

O peso relativo da preocupação com a promoção de cada um dos princípios de Boa Governança é idêntico em todas as áreas de intervenção do Ministério da Saúde?

A ação pública do Ministério da Saúde evidencia um nível semelhante de transversalidade da preocupação com a promoção de cada um dos princípios de Boa Governança?

\section{Princípios considerados de Boa Governança}

O conceito de Boa Governança surge pela primeira vez em 1989 num relatório do Banco Mundial ${ }^{11}$ e no contexto do apoio ao desenvolvimento, como forma de dar resposta à necessidade de avaliação da qualidade da governança dos Estados candidatos a programas de apoio. Esta matéria é alvo de maior destaque num relatório de 1992, intitulado Governance and Development. Nele, encontra-se uma primeira definição de governança como o modo como o poder é exercido na gestão dos recursos económicos e sociais de um país, para $o$ desenvolvimento ${ }^{12} \mathrm{e}$ abordam-se quatro áreas da governança: a gestão do sector público; a accountability; o quadro jurídico para o desenvolvimento; e, a informação e transparência. Ainda no âmbito da agenda do apoio ao desenvolvimento várias outras definições foram surgindo, por parte de instituições financiadoras, como é caso das Nações Unidas ${ }^{13,14}$, FMI ${ }^{15}$, Comissão Europeia ${ }^{16} \mathrm{e}$ $\mathrm{OCDE}^{17}$. Tendo surgido com foco nos países em desenvolvimento, o conceito de Boa Governança e os princípios que o estruturam estendeu-se à governação dos países desenvolvidos, em que, aliás, foi encontrar a inspiração para as boas práticas advogadas. Esta expansão da aplicação do conceito ficou particularmente patente nos países que tiveram de sofrer intervenções por parte das instâncias financiadoras internacionais, fruto da crise de 2008. Está também evidenciada na prossecução dos Objetivos do Desenvolvimento Sustentável (ODS), evidenciando a convergência dos diferentes países num ideal de desenvolvimento comum, ainda que de concretização diversa ${ }^{18}$.

Ao destacar a doutrina do Banco Mundial a propósito da Boa Governança, realça-se que esta incide sobre dois domínios: um técnico e o outro societal. No plano técnico, o Banco Mundial foca a capacidade institucional para a formulação e implementação de políticas amigas do desenvolvimento económico e da qualidade de vida. No plano societal, defende uma sociedade plural, em que as instâncias de governação estão abertas às expetativas e reivindicações da sociedade civil, acomodando-as na formulação das medidas prosseguidas. As preocupações técnicas recaem, no plano legal, sobre valores como justiça e liberdade, ou, no que à gestão das instituições respeita, na eficácia e eficiência. As preocupações societais enfatizam valores como legitimidade, accountability (prestação de contas e responsabilização), participação e transparência ${ }^{19}$.

Mais recentemente, a generalização da utilização do conceito, fez com que surgissem propostas de outros sectores, como é caso das associações da sociedade civil como o British and Irish Ombudsman Association (Bioa) ${ }^{20}$, o Chartered Institute of Public Finance and Accountancy (CIPFA) ${ }^{21,22}$ ou da academia, como é o caso de Rhodes ${ }^{7}$, Weiss ${ }^{23}$, de Hyden ${ }^{24}$ ou de Smith ${ }^{25}$, entre outros.

No contexto da saúde pública, o conceito de Boa Governança é visto como necessário e intelectualmente útil pela Organização Mundial de Saúde ${ }^{26}$, sendo a sua crescente relevância no sector reconhecida por especialistas, como é o caso de $B_{r a n d}{ }^{27}$. É encarado como um ideal a atingir através de um processo contínuo de melhoria, e 
considerado um requisito ético e um instrumento de mudança, que deve continuar a ganhar relevância na agenda da saúde.

Apesar do relativo consenso existente na metodologia de operacionalização do conceito - que consiste na identificação de princípios que devem orientar a intervenção do Estado e dos restantes stakeholders, para que seja melhorada a qualidade da governação - as propostas divergem significativamente no que diz respeito à definição dos princípios associados à Boa Governança.

Considerando os exemplos referidos anteriormente, é possível apurar um total de 24 princípios de Boa Governança, dos quais apenas cinco estão presentes em quase todas as propostas: responsabilização (accountability); eficácia e eficiência; transparência; participação dos stakeholders; e reforço do Estado de direito.

Neste estudo adotou-se a estrutura de princípios de Boa Governança usada pelas Nações Unidas $^{14}$, a qual inclui os cinco princípios enunciados anteriormente e que reúnem um consenso alargado, acrescidos dos princípios de: capacidade de resposta; orientação para o consenso; e, equidade e inclusão.

Entendemos ser útil acrescentar o princípio da independência, que retirámos da estrutura de princípios proposta pela British and Irish Ombudsman Association ${ }^{20}$.

Em síntese, na presente pesquisa foram considerados nove princípios de Boa Governança, cuja definição foi ajustada ao contexto da área da saúde e ao objeto de estudo em causa (Quadro 1).

\section{Operacionalização dos princípios de Boa Governança}

Cada iniciativa foi classificada em função da proximidade a cada um dos princípios de Boa Governança selecionados, com base em três critérios: natureza da iniciativa (relação com cada Área de Intervenção); objetivos/fins principais a atingir (especificidade da iniciativa); proximidade aos princípios de Boa Governança.

A cada iniciativa foram associados três princípios de Boa Governança, de acordo com a definição e o modelo de operacionalização apresentados no Quadro 1, permitindo a construção da matriz de associação que se apresenta no Quadro 3 e tornando possível analisar o nível de incidência de cada um dos princípios de Boa Governança. A associação foi efetuada a partir de uma análise de conteúdo de carácter extensivo a todos os documentos de caracterização de cada iniciativa a que foi possível ter acesso.
Para compensar a assimetria que se verifica na dimensão e abrangência das iniciavas, algumas delas foram divididas em subiniciativas, procurando-se melhorar, por esta via, a sua comparabilidade. A contabilização da ocorrência de cada um dos princípios de Boa Governança foi ponderada tendo em conta esta subdivisão, atribuindo-se a cada iniciativa um peso proporcional ao número de subiniciativas em que divide.

\section{Seleção e estruturação da amostra}

As ações tomadas pelo Governo de Portugal, na área da saúde e no período em análise, foram agrupadas em nove áreas, cuja tipologia foi construída de modo a corresponder às característicaschave (teóricas) associadas aos três paradigmas de governação referidos anteriormente e à aferição das práticas de Boa Governança.

Foram selecionadas 50 iniciativas levadas a cabo pelo Ministério da Saúde no período em análise, que constituem uma amostra muito próxima do universo - conforme se pode constatar no Quadro 2 -, com a sua seleção tido em consideração critérios de representatividade de cada uma das nove áreas de intervenção. As iniciativas analisadas distribuem-se pelas áreas de intervenção direta ou indireta do Ministério da Saúde.

\section{Recolha da informação sobre as iniciativas selecionadas}

O processo de recolha de informação iniciou-se com conversas exploratórias com várias entidades do Ministério da Saúde, com vista à identificação das medidas que haviam sido tomadas no sector da saúde, assim como de fontes de informação objetiva sobre a forma como estas foram estruturadas e de como se desenvolveu o processo de formulação e tomada de decisão. Este processo iniciou-se com a Secretaria-Geral do Ministério da Saúde, na pessoa da SecretáriaGeral, a Dra. Sandra Cavaca, tendo sido possível identificar as grandes preocupações do Ministro da Saúde em relação ao fortalecimento de práticas de Boa Governança em todo o Ministério e reconheceram-se, numa perspetiva global, os mecanismos de formulação e de difusão utilizados pela equipa Ministerial em relação às orientações e políticas emergentes (as já transpostas para um diploma legal, publicadas em Diário da República e implementadas, e ainda, as que se encontravam em processo de formulação). Destas primeiras conversas resultou também o agendamento de entrevistas presenciais exploratórias 
Quadro 1. Definição e operacionalização dos nove princípios de Boa Governança usados no estudo.

\begin{tabular}{|c|c|c|}
\hline $\begin{array}{c}\text { Princípios de } \\
\text { Boa Governança }\end{array}$ & Definição & Modelo de operacionalização \\
\hline $\begin{array}{l}\text { Responsabilização } \\
\text { (Accountability) }\end{array}$ & $\begin{array}{l}\text { Criar condições para obrigar as } \\
\text { organizações e seus responsáveis } \\
\text { a prestarem contas sobre } \\
\text { as suas ações e decisões aos } \\
\text { restantes stackholders e ao } \\
\text { público em geral. O princípio da } \\
\text { responsabilização está associado } \\
\text { aos princípios da transparência e } \\
\text { do reforço do Estado de Direito }\end{array}$ & $\begin{array}{l}\text { - Fortalecimento da transparência dos dados } \\
\text { (existência de sistemas de informação 24x7) } \\
\text { - Realização de reuniões regulares com os Dirigentes de } \\
\text { Topo do SNS } \\
\text { - Disponibilidade para esclarecer as entidades } \\
\text { supraministeriais e os restantes stakeholders } \\
\text { - Promoção da autonomia dos gestores } \\
\text { - Promoção da acreditação e da qualidade }\end{array}$ \\
\hline $\begin{array}{l}\text { Eficácia e } \\
\text { eficiência }\end{array}$ & $\begin{array}{l}\text { Criar condições para que se } \\
\text { produzam resultados que } \\
\text { satisfaçam as necessidades } \\
\text { da sociedade, com a melhor } \\
\text { utilização dos recursos } \\
\text { disponíveis, e que contribuam } \\
\text { para a redução de custos sem } \\
\text { sacrificar a qualidade dos } \\
\text { resultados }\end{array}$ & $\begin{array}{l}\text { - Promoção da redução de custos } \\
\text { - Recurso a análises de custo-benefício } \\
\text { - Análise e/ou promoção da sustentabilidade financeira } \\
\text { - Regulação e controlo do investimento } \\
\text { - Estímulo à redução das ineficiências } \\
\text { - Racionalização de espaços } \\
\text { - Rentabilização de equipamento instalado } \\
\text { - Reforço dos cuidados de saúde } \\
\text { - Reforço da promoção da saúde }\end{array}$ \\
\hline Transparência & $\begin{array}{l}\text { Criar condições para obrigar e } \\
\text { comprometer as instituições a } \\
\text { disponibilizar informação clara } \\
\text { e rigorosa que constitua uma } \\
\text { mais-valia para os restantes } \\
\text { stakeholders. Incluem-se todas } \\
\text { as iniciativas que promovam a } \\
\text { confiança dos stakeholders nos } \\
\text { processos de tomada de decisão } \\
\text { e na gestão }\end{array}$ & $\begin{array}{l}\text { - Fortalecimento da transparência dos dados } \\
\text { (existência de sistemas de informação 24x7) } \\
\text { - Renegociação dos acordos } \\
\text { - Inclusão nos acordos de análises custo-benefício } \\
\text { escrutináveis } \\
\text { - Fortalecimento das questões éticas } \\
\text { - Articulação com o Tribunal de Contas } \\
\text { - Intervenções públicas da equipa ministerial } \\
\text { - Promoção de avaliações externas - OMS, } \\
\text { Universidades }\end{array}$ \\
\hline $\begin{array}{l}\text { Participação dos } \\
\text { Stakeholders }\end{array}$ & $\begin{array}{l}\text { Criar condições para, de } \\
\text { forma organizada, envolver e } \\
\text { comprometer as partes, com } \\
\text { interesse nos resultados e na } \\
\text { sua efetividade. A participação } \\
\text { nos processos de tomada } \\
\text { de decisão pode efetuar-se } \\
\text { de forma direta ou indireta, } \\
\text { através de Instituições com } \\
\text { representatividade legitimada }\end{array}$ & $\begin{array}{l}\text { - Negociações e Acordos com stakeholders relevantes } \\
\text { da sociedade civil (Associações Profissionais ou de } \\
\text { Entidades) } \\
\text { - Articulação, em negociações, com os Ministérios das } \\
\text { Finanças e da Segurança Social } \\
\text { - Criação de condições para a participação em } \\
\text { negociações de Instituições do Ministério da Saúde de } \\
\text { gestão direta ou indireta }\end{array}$ \\
\hline $\begin{array}{l}\text { Reforço do Estado } \\
\text { de direito }\end{array}$ & $\begin{array}{l}\text { Contribuir para que exista um } \\
\text { enquadramento legal justo, } \\
\text { aplicado de forma efetiva e } \\
\text { imparcial, que sirva de suporte às } \\
\text { exigências de equidade e justiça }\end{array}$ & $\begin{array}{l}\text { - Realização de auditorias internas } \\
\text { - Realização de auditorias externas } \\
\text { - Reforço das inspeções } \\
\text { - Intervenções do Tribunal de Contas, da Polícia } \\
\text { Judiciária e do Ministério Público } \\
\text { - Reforço da intervenção da Entidade Reguladora da } \\
\text { Saúde (ERS) } \\
\text { - Criação de legislação sobre conflitos de interesses } \\
\text { - Promoção do combate à fraude }\end{array}$ \\
\hline
\end{tabular}

com o Gabinete Ministerial, ACSS-Administração Central do Sistema de Saúde, SPMS-Serviços Partilhados do Ministério da Saúde, IGAS-Ins- peção Geral das Atividades em Saúde, DGS-Direção Geral da Saúde, INFARMED-Autoridade Nacional do Medicamento e Produtos de Saúde, 
Quadro 1. Definição e operacionalização dos nove princípios de Boa Governança usados no estudo.

\begin{tabular}{|c|c|c|}
\hline $\begin{array}{c}\text { Princípios de } \\
\text { Boa Governança }\end{array}$ & Definição & Modelo de operacionalização \\
\hline $\begin{array}{l}\text { Capacidade } \\
\text { de resposta } \\
\text { (Responsiveness) }\end{array}$ & $\begin{array}{l}\text { Criar condições para que } \\
\text { o Ministério da Saúde e as } \\
\text { restantes entidades que dele } \\
\text { dependem, consigam dar aos } \\
\text { restantes stakeholders uma } \\
\text { resposta adequada, num prazo } \\
\text { razoável }\end{array}$ & $\begin{array}{l}\text { - Reforço da rede de cuidados de saúde } \\
\text { - Inovação na negociação com a indústria farmacêutica } \\
\text { - Criação de centros de referência } \\
\text { - Promoção da qualidade } \\
\text { - Reforço de recursos humanos e competências no SNS } \\
\text { - Reforço dos sistemas e tecnologias de informação no } \\
\text { SNS } \\
\text { - Promoção da saúde } \\
\text { - Promoção da prevenção da doença }\end{array}$ \\
\hline $\begin{array}{l}\text { Orientação para o } \\
\text { consenso }\end{array}$ & $\begin{array}{l}\text { Mediação dos diferentes } \\
\text { interesses no setor da saúde, } \\
\text { promovendo consensos } \\
\text { alargados em torno dos objetivos } \\
\text { a definir e da forma de os atingir }\end{array}$ & $\begin{array}{l}\text { - Participação, em negociações, dos Ministérios das } \\
\text { Finanças e da Segurança Social } \\
\text { - Participação, em negociações, de Instituições do } \\
\text { Ministério da Saúde de gestão direta ou indireta } \\
\text { - Participação, em negociações, do sector público, } \\
\text { social, academia e sociedade civil }\end{array}$ \\
\hline $\begin{array}{l}\text { Equidade e } \\
\text { inclusão }\end{array}$ & $\begin{array}{l}\text { Criar condições para assegurar } \\
\text { o acesso a cuidados de saúde a } \\
\text { todos os cidadãos, assumindo } \\
\text { que as suas necessidades e as suas } \\
\text { capacidades são diferentes }\end{array}$ & $\begin{array}{l}\text { - Melhoria do acesso a cuidados de saúde } \\
\text { - Promoção da qualidade no atendimento } \\
\text { - Criação/melhoria dos mecanismos de comunicação } \\
\text { com o utente } \\
\text { - Acesso mais favorável aos medicamentos } \\
\text { - Reforço da vacinação gratuita } \\
\text { - Promoção de uma maior ligação dos Conselhos } \\
\text { Consultivos dos Hospitais à região que servem }\end{array}$ \\
\hline Independência & $\begin{array}{l}\text { Criar condições para que as } \\
\text { decisões sejam tomadas sem } \\
\text { influência, pressão ou coação, } \\
\text { externa ou interna }\end{array}$ & $\begin{array}{l}\text { - Processos de compras por serviços partilhados } \\
\text { - Fortalecimento das questões éticas } \\
\text { - Promoção da autonomia de gestão } \\
\text { - Criação de legislação sobre conflitos de interesses e } \\
\text { regimes de incompatibilidade }\end{array}$ \\
\hline
\end{tabular}

Fonte: Adaptado para o presente estudo, a partir da estrutura de princípios de Boa Governança propostas pela UNESCAP ${ }^{14}$ e pela $\mathrm{Bioa}^{20}$.

entre outras. Nestas entrevistas foi apresentada a investigação em curso e a necessidade de a equipa do projeto obter informação das iniciativas daquelas instituições que se enquadrassem nos princípios de Boa Governança apresentados. A equipa de investigação teve acesso a toda a legislação relevante, a planos e relatórios de atividades, às intervenções da equipa Ministerial em diferentes fóruns ao longo do mandato, a relatórios de preparação das políticas, a pareceres de especialistas, a relatórios das práticas adotadas, a atas com os resultados de reuniões de decisão envolvendo múltiplos grupos com participantes de instituições de outros ministérios (Economia, Finanças, entre outros) e outras organizações (Sindicatos, Associações de Farmácias, Indústria Farmacêutica, Ordens etc.) Com base no acervo de informação recolhido, foram selecionadas e caracterizadas - incluindo aspetos do processo de negociação e tomada de decisão - 50 inicia- tivas e subiniciativas (ao todo trabalharam-se 86 tipos de ações postas em marcha pelo Ministério da Saúde neste período de 2011 a 2015), havendo sempre o cuidado de cruzar a informação obtida, de forma a garantir a sua fiabilidade. Foram ainda realizadas entrevistas complementares a organismos supra ministeriais como o Tribunal de Contas, na pessoa do Juiz Conselheiro responsável pela área da saúde, a Provedoria de Justiça, na pessoa do Chefe de Gabinete do Provedor e do Coordenador da área da saúde, e a CReSAP - Comissão de Recrutamento e Seleção para a Administração Pública, entidade administrativa independente responsável pelo recrutamento e seleção de candidatos para cargos de direção superior na Administração Central do Estado e avaliação de adequação de perfil de gestores públicos, na pessoa do seu Presidente. Destas conversas, para além do contributo fundamental para a compreensão do contexto e das iniciati- 
Quadro 2. Distribuição das 50 iniciativas analisadas pelas nove de áreas de intervenção (AIN) definidas.

\begin{tabular}{|c|c|c|c|}
\hline AIN & Orientação das iniciativas - principais objetivos & A & $\mathrm{C}$ \\
\hline Acordos & $\begin{array}{l}\text { Iniciativas que promoveram a negociação e o estabelecimento de acordos } \\
\text { com múltiplos atores externos ao Ministério da Saúde, mas com impacto } \\
\text { no desempenho do SNS. Destes acordos resultaram novas metodologias de } \\
\text { negociação, novos modelos contratuais, comissões de acompanhamento e } \\
\text { monitorização com a inclusão de todas as partes e, ainda, a montagem de processos } \\
\text { que permitem a avaliação da efetividade dos acordos com base em informação } \\
\text { transparente para os atores. }\end{array}$ & 7 & $95 \%$ \\
\hline $\begin{array}{l}\text { Cidadão no } \\
\text { Centro do } \\
\text { SNS }\end{array}$ & $\begin{array}{l}\text { Para além de contínuas ações de promoção da saúde, inclui as iniciativas dirigidas } \\
\text { à promoção de um maior acesso a cuidados de saúde por parte dos mais idosos } \\
\text { e vulneráveis. Inclui ainda: as reformulações das redes dos cuidados paliativos } \\
\text { e continuados; as nomeações dos Presidentes dos Conselhos Consultivos dos } \\
\text { hospitais ( } 41 \text { nomeações de } 2012 \text { a 2015) que têm por missão incluir o cidadão na } \\
\text { estratégia e administração do hospital ou da unidade local de saúde. }\end{array}$ & 9 & $30 \%$ \\
\hline $\begin{array}{l}\text { Comunicação } \\
\text { e ações com } \\
\text { Stakeholders }\end{array}$ & $\begin{array}{l}\text { Iniciativas dedicadas a estabelecer fluxos de informação e de prestação de contas } \\
\text { aos stakeholders sobre os projetos, ações e resultados do desempenho do Ministério } \\
\text { da Saúde. Esta área foi fortemente impulsionada pela ACSS por disponibilizar } \\
\text { dados para benchmarking de hospitais e ACES. Outra iniciativa prende-se com a } \\
\text { multiplicidade de vezes que Ministro e responsáveis do Ministério se deslocaram } \\
\text { à Assembleia da República para responder perante as comissões parlamentares e o } \\
\text { plenário. } \\
\text { Verificou-se igualmente a existência de reuniões quadrimestrais, de ponto de } \\
\text { situação, do Ministro da Saúde com os dirigentes do Ministério. }\end{array}$ & 3 & $90 \%$ \\
\hline Eficiência & $\begin{array}{l}\text { Iniciativas dirigidas à melhoria da sustentabilidade do SNS, como é o caso da } \\
\text { monitorização da despesa no circuito do medicamento e dos dispositivos médicos; } \\
\text { prestação de informação ao cidadão/utente sobre o real valor dos tratamentos } \\
\text { ministrados em relação aos pagamentos que faz ou de que está isento e, ainda, } \\
\text { iniciativas reparadoras do desequilíbrio financeiro dos hospitais; iniciativas } \\
\text { destinadas à atualização/orientação nacional dos equipamentos pesados em saúde; } \\
\text { iniciativas de combate ao desperdício (ex: programa de racionalização de ocupação } \\
\text { de espaço e controlo dos pagamentos, pelo Centro de Conferência de Faturas e a } \\
\text { análise da Inspeção Geral de Finanças sobre a despesa paga, ao abrigo dos prazos } \\
\text { de regularização de dívidas). }\end{array}$ & 8 & $50 \%$ \\
\hline Controlo & $\begin{array}{l}\text { Iniciativas dirigidas para a melhoria da gestão de todas as instituições do } \\
\text { Ministério através do reforço dos mecanismos continuados de verificação da boa } \\
\text { gestão, da identificação de boas e más práticas e da elaboração de propostas de } \\
\text { recomendações. Estas inspeções e auditorias são da responsabilidade de todas as } \\
\text { entidades do Ministério através dos auditores internos, das estruturas de inspeção } \\
\text { (Inspeção Geral das Atividades em Saúde) e da estrutura reguladora (Entidade } \\
\text { Reguladora da Saúde) e ainda, de entidades externas ao Ministério (Tribunal de } \\
\text { Contas). }\end{array}$ & 9 & $95 \%$ \\
\hline Ética & $\begin{array}{l}\text { Iniciativas dirigidas ao fortalecimento das questões de ética em todas as } \\
\text { instituições do Ministério, permitindo mais interações baseadas na confiança e } \\
\text { reguladas por um conjunto de normas negociadas e acordadas pelos participantes } \\
\text { na rede interna (incluem-se as regras que asseguram a proteção dos conflitos de } \\
\text { interesses entre os profissionais do Ministério) e externa do SNS. Incluem-se as } \\
\text { Comissões do Conselho Nacional de Ética para as Ciências da Vida (CNECV) e a } \\
\text { Comissão de Ética para a Investigação Clínica (CEIC). }\end{array}$ & 4 & $95 \%$ \\
\hline $\begin{array}{l}\text { Combate à } \\
\text { Fraude }\end{array}$ & $\begin{array}{l}\text { Iniciativas dirigidas para o combate à fraude e ao desperdício. Para tal, o Ministério } \\
\text { acentuou não só a deteção de situações anómalas através do Centro de Conferência } \\
\text { de Faturas como a articulação com a Polícia Judiciária e o Ministério Público. O } \\
\text { ministério durante este período reforçou por duas vezes o quadro de inspetores da } \\
\text { Inspeção Geral das Atividades em Saúde. }\end{array}$ & 3 & $95 \%$ \\
\hline
\end{tabular}


Quadro 2. Distribuição das 50 iniciativas analisadas pelas nove de áreas de intervenção (AIN) definidas.

\begin{tabular}{|l|l|c|c|}
\hline \multicolumn{1}{|c|}{ AIN } & \multicolumn{1}{|c|}{ Orientação das iniciativas - principais objetivos } & A & C \\
\hline $\begin{array}{l}\text { Inovação nos } \\
\text { Processos }\end{array}$ & $\begin{array}{l}\text { Iniciativas dirigidas para a inovação e modernização administrativa, } \\
\text { nomeadamente, no setor das Compras e no desenvolvimento de sistemas e } \\
\text { tecnologias de informação. Através de plataformas horizontais e interoperáveis, } \\
\text { que envolvam todas as instituições hospitalares e de cuidados primários, as } \\
\text { entidades centrais da administração da saúde e o cidadão, potenciando a interação } \\
\text { com o SNS através de meios digitais. Como exemplo, referimos o registo de saúde } \\
\text { eletrónico, a plataforma de dados de saúde, a prescrição eletrónica médica e a } \\
\text { desmaterialização da receita }\end{array}$ & $30 \%$ \\
\hline Qualidade & $\begin{array}{l}\text { Iniciativas destinadas a assegurar maior qualidade aos utentes do SNS, tais como, } \\
\text { o combate às infeções nosocomiais, a criação das normas de orientação clínica e } \\
\text { os mecanismos para a sua monitorização, a diminuição das taxas de cesarianas e, } \\
\text { ainda, iniciativas destinadas a dar mais segurança de cuidados de saúde, como o } \\
\text { cartão pessoal de doenças raras, o combate aos antibióticos, o sistema nacional } \\
\text { de notificação de incidentes, entre outros. Nesta área incluímos a acreditação } \\
\text { dos sistemas de qualidade nos hospitais e ACES iniciadas, em curso e finalizadas } \\
\text { neste período, assim como, o reforço dos recursos humanos e sua capacitação na } \\
\text { atividade assistencial }\end{array}$ & 4 & $50 \%$ \\
\hline
\end{tabular}

A = Número de medidas analisadas em cada área de intervenção (amostra); C = grau de cobertura das medidas analisadas em relação ao total de medidas levadas a cabo (universo).

Fonte: Elaborado pelos autores.

vas, foi também possível obter informação sobre a perceção que estes stakeholders tinham sobre a ação do Governo na área da saúde - que, genericamente, era de que existia uma grande abertura para o diálogo e cooperação por parte da equipa ministerial -, mas como o enfoque deste estudo não eram as perceções dos stakeholders sobre a ação do governo, optou-se por não se considerar a informação recolhida, a qual incida essencialmente sobre a avaliação que estes stakeholders faziam da participação/cooperação da sua Instituição com a equipa ministerial.

\section{Análise e discussão dos resultados}

Em recorrência à metodologia descrita, a construção da matriz de associação entre as 50 iniciativas analisadas e os nove princípios de Boa Governança (Quadro 3), permitiu - não considerando a segmentação por áreas de intervenção - obter o peso relativo global de cada um dos princípios de Boa Governança. Da análise destes pesos relativos verificou-se uma predominância dos princípios da "eficácia/eficiência" e da "transparência", com um peso relativo conjunto de $44 \%$, indicando uma clara preocupação do Ministério da Saúde em promover a satisfação das necessidades dos utentes com uma utilização racional dos recursos e em promover a confiança dos vários stakeholders nos processos de tomada de decisão.

No caso da preocupação com a "eficiência/ eficácia”, nos parece legítimo assumir que resulta em boa parte de uma imposição do $M o U$, a preocupação com a transparência, no nosso entender e no da maioria dos entrevistados nas conversas exploratórias, se deve atribuir a um reflexo da forma de atuar da equipa ministerial.

A melhoria da "capacidade de resposta" do sistema de saúde - condizentes às necessidades dos utentes - a "responsabilização (accountability)" pelas decisões tomadas e o contributo para o "reforço do Estado de direito" - criando condições para que exista na área da saúde um sistema legal justo e aplicado de forma efetiva e imparcial - foram também preocupações visíveis na atuação do Ministério da Saúde, assumindo um peso relativo conjunto de $35 \%$.

As preocupações com a "participação dos stakeholders" nos processos de tomada de decisão, com a "equidade" no acesso aos cuidados de saúde, com a "garantia da independência" dos gestores e com a criação de "consensos" em torno dos principais objetivos a definir e da forma de os atingir, também estão presentes na atuação da equipa ministerial e apresentam um peso relativo conjunto de $21 \%$. 


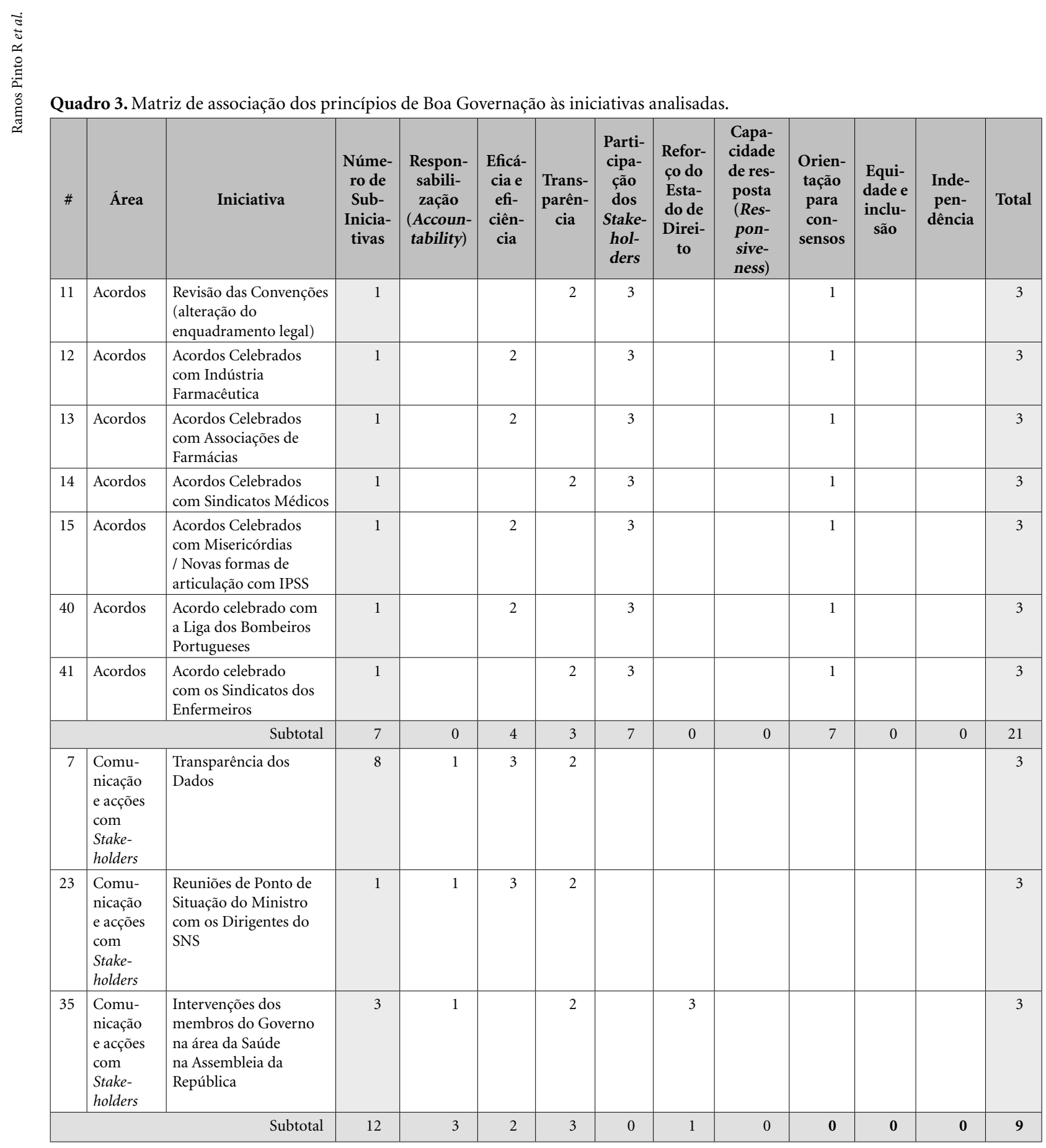

continua

\section{Análise por área de intervenção}

Quando se analisam os dados da matriz de associação (Quadro 3) tendo em consideração a agregação das iniciativas em áreas de inter- venção, torna-se possível segmentar a análise do peso relativo de cada um dos princípios de Boa Governança. A análise do grau de incidência dos princípios nas diferentes áreas de intervenção, evidencia uma significativa diferença entre áreas.

O número significativo de áreas de interven- 
Quadro 3. Matriz de associação dos princípios de Boa Governação às iniciativas analisadas.

\begin{tabular}{|c|c|c|c|c|c|c|c|c|c|c|c|c|c|}
\hline$\#$ & Área & Iniciativa & $\begin{array}{l}\text { Núme- } \\
\text { ro de } \\
\text { Sub- } \\
\text { Inicia- } \\
\text { tivas }\end{array}$ & $\begin{array}{l}\text { Respon- } \\
\text { sabili- } \\
\text { zação } \\
\text { (Accoun- } \\
\text { tability) }\end{array}$ & $\begin{array}{l}\text { Eficá- } \\
\text { cia e } \\
\text { efi- } \\
\text { ciên- } \\
\text { cia }\end{array}$ & $\begin{array}{l}\text { Trans- } \\
\text { parên- } \\
\text { cia }\end{array}$ & $\begin{array}{c}\text { Parti- } \\
\text { cipa- } \\
\text { ção } \\
\text { dos } \\
\text { Stake- } \\
\text { hol- } \\
\text { ders }\end{array}$ & $\begin{array}{c}\text { Refor- } \\
\text { ço do } \\
\text { Esta- } \\
\text { do de } \\
\text { Direi- } \\
\text { to }\end{array}$ & $\begin{array}{c}\text { Capa- } \\
\text { cidade } \\
\text { de res- } \\
\text { posta } \\
\text { (Res- } \\
\text { pon- } \\
\text { sive- } \\
\text { ness) }\end{array}$ & $\begin{array}{l}\text { Orien- } \\
\text { tação } \\
\text { para } \\
\text { con- } \\
\text { sensos }\end{array}$ & $\begin{array}{l}\text { Equi- } \\
\text { dade e } \\
\text { inclu- } \\
\text { são }\end{array}$ & $\begin{array}{l}\text { Inde- } \\
\text { pen- } \\
\text { dência }\end{array}$ & Total \\
\hline 8 & Eficiência & $\begin{array}{l}\text { Emissão da nota } \\
\text { informativa de custos }\end{array}$ & 1 & 3 & 1 & 2 & & & & & & & 3 \\
\hline 9 & Eficiência & $\begin{array}{l}\text { Diminuição de margens } \\
\text { excessivas /opacidade } \\
\text { dos preços }\end{array}$ & 1 & & 1 & 2 & 3 & & & & & & 3 \\
\hline 10 & Eficiência & $\begin{array}{l}\text { Acordos com análise } \\
\text { custo/ benefício } \\
\text { escrutináveis }\end{array}$ & 1 & & 1 & 2 & 3 & & & & & & 3 \\
\hline 16 & Eficiência & \begin{tabular}{|lr} 
Inclusão dos & Hospitais \\
EPE no & perímetro \\
Orçamental & da \\
Administração & Central \\
\end{tabular} & 1 & 2 & 1 & 3 & & & & & & & 3 \\
\hline 42 & Eficiência & $\begin{array}{l}\text { Evolução da Autonomia } \\
\text { dos Conselhos de } \\
\text { Administração das EPE }\end{array}$ & 1 & 2 & 1 & & & & & & & 3 & 3 \\
\hline 44 & Eficiência & $\begin{array}{l}\text { Inclusão da ADSE no } \\
\text { Ministério da Saúde }\end{array}$ & 1 & & 1 & & & & 2 & & 3 & & 3 \\
\hline 45 & Eficiência & $\begin{array}{ll}\text { Programa } & \text { de } \\
\text { Racionalização } & \text { da } \\
\text { Ocupação dos Espaços }\end{array}$ & 1 & & 1 & & 3 & & & 2 & & & 3 \\
\hline 46 & Eficiência & $\begin{array}{l}\text { Carta de Equipamentos } \\
\text { Pesados }\end{array}$ & 1 & & 1 & & 3 & & 2 & & & & 3 \\
\hline & & Subtotal & 8 & 3 & 8 & 4 & 4 & 0 & 2 & 1 & 1 & 1 & 24 \\
\hline 1 & Controlo & $\begin{array}{l}\text { Auditorias Externas a } \\
\text { todas as Unidades do } \\
\text { SNS }\end{array}$ & 1 & 2 & & 3 & & 1 & & & & & 3 \\
\hline 2 & Controlo & \begin{tabular}{|lr} 
Nomeação & dos \\
responsáveis & dos \\
Gabinetes de & Auditoria \\
Interna & \\
\end{tabular} & 1 & 2 & & 3 & & 1 & & & & & 3 \\
\hline 5 & Controlo & $\begin{array}{l}\text { Reforço da Inspecção } \\
\text { Geral das Actividades } \\
\text { em Saúde }\end{array}$ & 1 & 2 & & 3 & & 1 & & & & & 3 \\
\hline 6 & Controlo & $\begin{array}{l}\text { Reforço de competências } \\
\text { de licenciamento e } \\
\text { avaliação da ERS }\end{array}$ & 1 & 2 & & 3 & & 1 & & & & & 3 \\
\hline 43 & Controlo & $\begin{array}{l}\text { Monitorização das } \\
\text { medidas do } \mathrm{MoU}\end{array}$ & 1 & & 2 & 3 & & 1 & & & & & 3 \\
\hline 28 & Controlo & $\begin{array}{|ll|}\text { Intervenções } & \text { do } \\
\text { Tribunal de Contas } & \\
\end{array}$ & 1 & 2 & & 3 & & 1 & & & & & 3 \\
\hline 33 & Controlo & $\begin{array}{l}\text { Alterações da Legislação } \\
\text { das Ordens }\end{array}$ & 1 & 2 & & 3 & & 1 & & & & & 3 \\
\hline 47 & Controlo & $\begin{array}{l}\text { Solicitação pelo MS de } \\
\text { um Auditor Jurídico }\end{array}$ & 1 & 2 & & 3 & & 1 & & & & & 3 \\
\hline 48 & Controlo & Avaliação Externa & 7 & 2 & & 3 & & 1 & & & & & 3 \\
\hline \multicolumn{3}{|r|}{ Subtotal } & 15 & 8 & 1 & 9 & $\mathbf{0}$ & 9 & 0 & 0 & $\mathbf{0}$ & 0 & 27 \\
\hline
\end{tabular}

continua

ção e de princípios gera um elevado número de pesos relativos, que se tornam complicados de analisar. O Quadro 4 procura facilitar esta tare- fa, dando evidência das diferenças das incidências dos princípios de Boa Governança nas várias áreas de intervenção, identificando para cada 


\begin{tabular}{|c|c|c|c|c|c|c|c|c|c|c|c|c|c|}
\hline$\#$ & Área & Iniciativa & $\begin{array}{l}\text { Núme- } \\
\text { ro de } \\
\text { Sub- } \\
\text { Inicia- } \\
\text { tivas }\end{array}$ & $\begin{array}{l}\text { Respon- } \\
\text { sabili- } \\
\text { zação } \\
\text { (Accoun- } \\
\text { tability) }\end{array}$ & $\begin{array}{l}\text { Eficá- } \\
\text { cia e } \\
\text { efi- } \\
\text { ciên- } \\
\text { cia }\end{array}$ & $\begin{array}{l}\text { Trans- } \\
\text { parên- } \\
\text { cia }\end{array}$ & $\begin{array}{c}\text { Parti- } \\
\text { cipa- } \\
\text { ção } \\
\text { dos } \\
\text { Stake- } \\
\text { hol- } \\
\text { ders }\end{array}$ & $\begin{array}{c}\text { Refor- } \\
\text { ço do } \\
\text { Esta- } \\
\text { do de } \\
\text { Direi- } \\
\text { to }\end{array}$ & $\begin{array}{c}\text { Capa- } \\
\text { cidade } \\
\text { de res- } \\
\text { posta } \\
\text { (Res- } \\
\text { pon- } \\
\text { sive- } \\
\text { ness) } \\
\end{array}$ & $\begin{array}{c}\text { Orien- } \\
\text { tação } \\
\text { para } \\
\text { con- } \\
\text { sensos }\end{array}$ & $\begin{array}{c}\text { Equi- } \\
\text { dade e } \\
\text { inclu- } \\
\text { são }\end{array}$ & $\begin{array}{l}\text { Inde- } \\
\text { pen- } \\
\text { dência }\end{array}$ & Total \\
\hline 3 & Ética & \begin{tabular}{|lr} 
Legislação & sobre \\
Conflitos & de \\
Interesse e Regime & de \\
Incompatibilidades
\end{tabular} & 1 & & & 2 & & 1 & & & & 3 & 3 \\
\hline 17 & Ética & Código de Ética no SNS & 1 & & & 2 & & 1 & & & & 3 & 3 \\
\hline 36 & Ética & $\begin{array}{l}\text { Intervenção do CNECV } \\
\text { e da CEIC }\end{array}$ & 1 & & & 2 & & 1 & & & & 3 & 3 \\
\hline 49 & Ética & \begin{tabular}{|lr} 
Comissão & para \\
a & procriação \\
medicamente assistida
\end{tabular} & 1 & & & 2 & & 1 & & & & 3 & 3 \\
\hline & & Subtotal & 4 & 0 & 0 & 4 & 0 & 4 & 0 & 0 & 0 & 4 & 12 \\
\hline 4 & \begin{tabular}{|l} 
Cidadão \\
no \\
Centro \\
do SNS
\end{tabular} & $\begin{array}{l}\text { Dinamização } \\
\text { dos Conselhos } \\
\text { Consultivos }\end{array}$ & 1 & & 3 & & & & 2 & & 1 & & 3 \\
\hline 20 & $\begin{array}{l}\text { Cidadão } \\
\text { no } \\
\text { Centro } \\
\text { do SNS }\end{array}$ & $\begin{array}{l}\text { Gilead - Hepatite C } \\
-2015\end{array}$ & 1 & & 3 & & & & 2 & & 1 & & 3 \\
\hline 21 & $\begin{array}{l}\text { Cidadão } \\
\text { no } \\
\text { Centro } \\
\text { do SNS } \\
\end{array}$ & $\begin{array}{l}\text { Saúde mais acessivel } \\
\text { para os mais } \\
\text { vulneráveis }\end{array}$ & 1 & & 3 & & & & 2 & & 1 & & 3 \\
\hline 22 & $\begin{array}{l}\text { Cidadão } \\
\text { no } \\
\text { Centro } \\
\text { do SNS } \\
\end{array}$ & $\begin{array}{l}\text { Melhoria do acesso ao } \\
\text { medicamento }\end{array}$ & 1 & & 3 & & & & 2 & & 1 & & 3 \\
\hline 24 & $\begin{array}{l}\text { Cidadão } \\
\text { no } \\
\text { Centro } \\
\text { do SNS } \\
\end{array}$ & $\begin{array}{l}\text { Rede de Cuidados } \\
\text { Paliativos }\end{array}$ & 1 & & 3 & & & & 2 & & 1 & & 3 \\
\hline 25 & $\begin{array}{l}\text { Cidadão } \\
\text { no } \\
\text { Centro } \\
\text { do SNS }\end{array}$ & $\begin{array}{l}\text { Reforço Rede } \\
\text { de Cuidados } \\
\text { Continuados }\end{array}$ & 1 & & 3 & & & & 2 & & 1 & & 3 \\
\hline 26 & $\begin{array}{l}\text { Cidadão } \\
\text { no } \\
\text { Centro } \\
\text { do SNS } \\
\end{array}$ & $\begin{array}{l}\text { Vacinação Gratuita } \\
\text { Gripe }>65 \text { anos e } \\
\text { Prevenar } 13\end{array}$ & 1 & & 3 & & & & 2 & & 1 & & 3 \\
\hline 27 & \begin{tabular}{|l} 
Cidadão \\
no \\
Centro \\
do SNS \\
\end{tabular} & Linha Saúde 24 Sénior & 1 & & 3 & & & & 2 & & 1 & & 3 \\
\hline 38 & $\begin{array}{l}\text { Cidadão } \\
\text { no } \\
\text { Centro } \\
\text { do SNS }\end{array}$ & $\begin{array}{l}\text { Promoção da Saúde / } \\
\text { Prevenção da doença } \\
\text { (tabaco, alcoolismo, } \\
\text { drogas / smartshops }\end{array}$ & 1 & & 3 & & & & 2 & & 1 & & 3 \\
\hline \multicolumn{3}{|r|}{ Subtotal } & 9 & 0 & 9 & 0 & 0 & 0 & 9 & 0 & 9 & 0 & 27 \\
\hline
\end{tabular}


Quadro 3. Matriz de associação dos princípios de Boa Governação às iniciativas analisadas.

\begin{tabular}{|c|c|c|c|c|c|c|c|c|c|c|c|c|c|}
\hline$\#$ & Área & Iniciativa & $\begin{array}{l}\text { Núme- } \\
\text { ro de } \\
\text { Sub- } \\
\text { Inicia- } \\
\text { tivas }\end{array}$ & $\begin{array}{l}\text { Respon- } \\
\text { sabili- } \\
\text { zação } \\
\text { (Accoun- } \\
\text { tability) }\end{array}$ & $\begin{array}{c}\text { Eficá- } \\
\text { cia e } \\
\text { efi- } \\
\text { ciên- } \\
\text { cia }\end{array}$ & $\begin{array}{l}\text { Trans- } \\
\text { parên- } \\
\text { cia }\end{array}$ & $\begin{array}{c}\text { Parti- } \\
\text { cipa- } \\
\text { ção } \\
\text { dos } \\
\text { Stake- } \\
\text { hol- } \\
\text { ders }\end{array}$ & $\begin{array}{l}\text { Refor- } \\
\text { ço do } \\
\text { Esta- } \\
\text { do de } \\
\text { Direi- } \\
\text { to }\end{array}$ & $\begin{array}{c}\text { Capa- } \\
\text { cidade } \\
\text { de res- } \\
\text { posta } \\
\text { (Res- } \\
\text { pon- } \\
\text { sive- } \\
\text { ness) }\end{array}$ & $\begin{array}{c}\text { Orien- } \\
\text { tação } \\
\text { para } \\
\text { con- } \\
\text { sensos }\end{array}$ & $\begin{array}{l}\text { Equi- } \\
\text { dade e } \\
\text { inclu- } \\
\text { são }\end{array}$ & $\begin{array}{l}\text { Inde- } \\
\text { pen- } \\
\text { dência }\end{array}$ & Total \\
\hline 18 & $\begin{array}{l}\text { Combate } \\
\text { à fraude }\end{array}$ & $\begin{array}{l}\text { Infraestruturas de } \\
\text { Combate à Fraude } \\
\end{array}$ & 3 & & 2 & & 3 & 1 & & & & & 3 \\
\hline 31 & $\begin{array}{l}\text { Combate } \\
\text { à fraude }\end{array}$ & Intervenções da PJ & 1 & & 2 & 3 & & 1 & & & & & 3 \\
\hline 32 & $\begin{array}{l}\text { Combate } \\
\text { à fraude }\end{array}$ & \begin{tabular}{|l|} 
Intervenções do \\
Ministério Público
\end{tabular} & 1 & & 2 & 3 & & 1 & & & & & 3 \\
\hline & & Sub-Total & 5 & 0 & 3 & 2 & 1 & 3 & 0 & 0 & 0 & 0 & 9 \\
\hline 30 & \begin{tabular}{|l} 
Inovação \\
nos \\
processos
\end{tabular} & $\begin{array}{l}\text { Processos de Compras } \\
\text { da SGMS }\end{array}$ & 1 & & 1 & 3 & & & & & & 2 & 3 \\
\hline 29 & \begin{tabular}{|l} 
Inovação \\
nos \\
processos \\
\end{tabular} & $\begin{array}{l}\text { Processos de Compras } \\
\text { dos SPMS }\end{array}$ & 1 & & 1 & 3 & & & & & & 2 & 3 \\
\hline 37 & $\begin{array}{l}\text { Inovação } \\
\text { nos } \\
\text { processos }\end{array}$ & $\begin{array}{l}\text { Sistemas e Tecnologias } \\
\text { de Informação no } \\
\text { SNS }\end{array}$ & 15 & & 1 & 3 & & & 2 & & & & 3 \\
\hline & & Subtotal & 17 & 0 & 3 & 3 & 0 & 0 & 1 & 0 & 0 & 2 & 9 \\
\hline 34 & \begin{tabular}{|l} 
Quali- \\
dade
\end{tabular} & \begin{tabular}{|l|} 
Acreditações - \\
Sistemas de Qualidade \\
\end{tabular} & 1 & 2 & 3 & & & & 1 & & & & 3 \\
\hline 39 & $\begin{array}{l}\text { Quali- } \\
\text { dade }\end{array}$ & $\begin{array}{l}\text { Reforço dos Recursos } \\
\text { Humanos e das } \\
\text { competências das } \\
\text { Chefias }\end{array}$ & 1 & & 2 & 3 & & & 1 & & & & 3 \\
\hline 50 & $\begin{array}{l}\text { Quali- } \\
\text { dade }\end{array}$ & Qualidade na Saúde & 6 & & & & 3 & & 1 & & 2 & & 3 \\
\hline 19 & $\begin{array}{l}\text { Quali- } \\
\text { dade }\end{array}$ & Centros de referência & 1 & & 3 & & & & 1 & & 2 & & 3 \\
\hline & & Subtotal & 9 & 1 & 3 & 1 & 1 & 0 & 4 & 0 & 2 & 0 & 12 \\
\hline & & Total & 86 & 15 & 33 & 29 & 13 & 17 & 16 & 8 & 12 & 7 & 150 \\
\hline \multicolumn{3}{|c|}{ Peso global de cada princípio } & - & $10 \%$ & $22 \%$ & $19 \%$ & $9 \%$ & $11 \%$ & $11 \%$ & $5 \%$ & $8 \%$ & $5 \%$ & - \\
\hline
\end{tabular}

Fonte: Elaborado pelos autores.

princípio as áreas de intervenção com incidência máxima. Cada iniciativa é associada a três princípios de Boa Governança, o que implica que a incidência de cada princípio é, no máximo, de 33\%.

Num primeiro nível, temos o princípio da "eficácia/eficiência" que está presente com incidência máxima em quatro das nove áreas de intervenção, seguido dos princípios de "transparência" e "reforço do Estado de Direito", presentes com incidência máxima em três áreas. Esta evidência reforça as conclusões indicadas no ponto anterior e indicia uma transversalidade na aplicação destes princípios. Num segundo nível, encontram-se os princípios da "capacidade de resposta (responsiveness)", com incidência máxima em duas áreas de intervenção e os princípios da "participação de stakeholders", da "orientação para consensos" e da "independência", que têm incidência máxima em apenas uma área.

\section{Análise por princípio de Boa Governança}

Com o objetivo de se tentar perceber melhor a forma como os princípios de Boa Governança foram aplicados em cada uma das áreas de intervenção, fez-se a leitura inversa do quadro de associa- 
ção apresentada (Quadro 3), calculando-se o peso relativo de cada área de intervenção na incidência de cada um dos princípios de Boa Governança.

Analisando os dados na perspetiva dos princípios de Boa Governança, verifica-se que o peso das áreas de intervenção em cada princípio varia significativamente, sendo possível identificar dois comportamentos distintos: 1) princípios com uma incidência mais transversal (dispersão máxima) e que estão presentes, ainda que com pesos variáveis, em várias das áreas de intervenção; 2) princípios cuja incidência se concentra essencialmente numa área de intervenção (concentração máxima), a qual atinge um peso relativo superior a $50 \%$. Com o intuito de facilitar a análise destes dois comportamentos, construiu-se o gráfico 1 , em que cada princípio de Boa Governança é representado em função do número de aéreas de intervenção a que é associado.

Note-se que, neste ponto, não se trata de analisar o grau de incidência global dos princípios de Boa Governança, mas de aferir o seu nível de dispersão (transversalidade) pelas diferentes áreas de intervenção. No Gráfico 1, por exemplo, o princí-

Quadro 4. Identificação das áreas de intervenção em que cada um dos princípios de Boa Governança tem uma incidência relevante.

\begin{tabular}{|l|l|}
\hline \multicolumn{1}{|c|}{$\begin{array}{c}\text { Princípio de } \\
\text { Boa Governança }\end{array}$} & $\begin{array}{l}\text { Área(s) de intervenção } \\
\text { em que o princípio tem } \\
\text { uma incidência máxima }\end{array}$ \\
\hline Eficácia e Eficiência & $\begin{array}{l}\text { Eficiência } \\
\text { Cidadão no centro do SNS } \\
\text { Combate à fraude } \\
\text { Inovação nos processos }\end{array}$ \\
\hline Transparência & $\begin{array}{l}\text { Controlo } \\
\text { Ética } \\
\text { Inovação nos processos }\end{array}$ \\
\hline $\begin{array}{l}\text { Reforço do Estado de } \\
\text { Direito }\end{array}$ & $\begin{array}{l}\text { Controlo } \\
\text { Ética } \\
\text { Combate à fraude }\end{array}$ \\
\hline $\begin{array}{l}\text { Capacidade de Resposta } \\
\text { (Responsiveness) }\end{array}$ & $\begin{array}{l}\text { Cidadão no centro do SNS } \\
\text { Qualidade }\end{array}$ \\
\hline $\begin{array}{l}\text { Responsabilização } \\
\text { (Accountability) }\end{array}$ & $\begin{array}{l}\text { Comunicação e ações com } \\
\text { stakeholders } \\
\text { Controlo }\end{array}$ \\
\hline Equidade e Inclusão & Cidadão no centro do SNS \\
\hline $\begin{array}{l}\text { Participação dos } \\
\text { Stakeholders }\end{array}$ & Acordos \\
\hline $\begin{array}{l}\text { Orientação para } \\
\text { consensos }\end{array}$ & Acordos \\
\hline Independência & Ética \\
\hline
\end{tabular}

Fonte: Elaborado pelos autores. pio da transparência aparece associado a oito das nove áreas analisadas, independentemente do seu grau de incidência em cada uma das áreas.

No Gráfico 1 é possível identificar três perfis de comportamento: 1) os princípios que demonstram uma aplicação mais transversal por parte do Ministério da Saúde são claramente o da "transparência" e o da "eficácia/eficiência", presentes em oito das nove áreas de intervenção, embora o seu grau de incidência em cada uma das áreas não ultrapasse os $29 \%$ no caso da "transparência" e de 30\% no caso da "eficácia/ eficiência"; 2) os princípios da "participação dos stakeholders", "capacidade de resposta (responsiveness)" e da "responsabilização (accountability)", com um grau de transversalidade menor, mas ainda sem ter uma área de intervenção com um peso relativo superior a $50 \%$; 3 ) os princípios de "orientação para consensos", "independência", "equidade e inclusão" e "reforço do Estado de direito", com uma predominância clara de uma das áreas de intervenção, a qual apresenta um peso relativo claramente superior a $50 \%$.

No Gráfico 2 encontram-se representados os princípios de Boa Governança que se enquadram no terceiro perfil identificado no Gráfico 1, com a indicação da área de intervenção predominante e o respetivo peso relativo.

Estes resultados surgem como expectáveis. Com efeito, o processo de agregação das iniciativas por áreas de intervenção (ex: iniciativas na área dos Acordos) associa, em alguns casos, de forma mais imediata (como é o caso das quatro áreas indicadas no gráfico 2) uma determinada área a um determinado princípio de Boa Governança (ex: a área dos acordos associa-se mais naturalmente ao princípio da "orientação para consensos", o que explica a sua grande concentração quando analisamos especificamente este princípio).

\section{Conclusões}

No que diz respeito à análise da qualidade da governança do sector da saúde, no período em análise, e usando como critério a aplicação dos princípios da Boa Governança, é possível, em termos globais, concluir que existiu uma clara predominância dos princípios da "transparência" e da "eficácia/eficiência". A ação pública do Ministério da Saúde transparece uma clara preocupação com a promoção da satisfação das necessidades dos utentes com uma utilização racional dos recursos e com a adoção de medidas que estimulem a confiança dos vários stakeholders nos processos de to- 


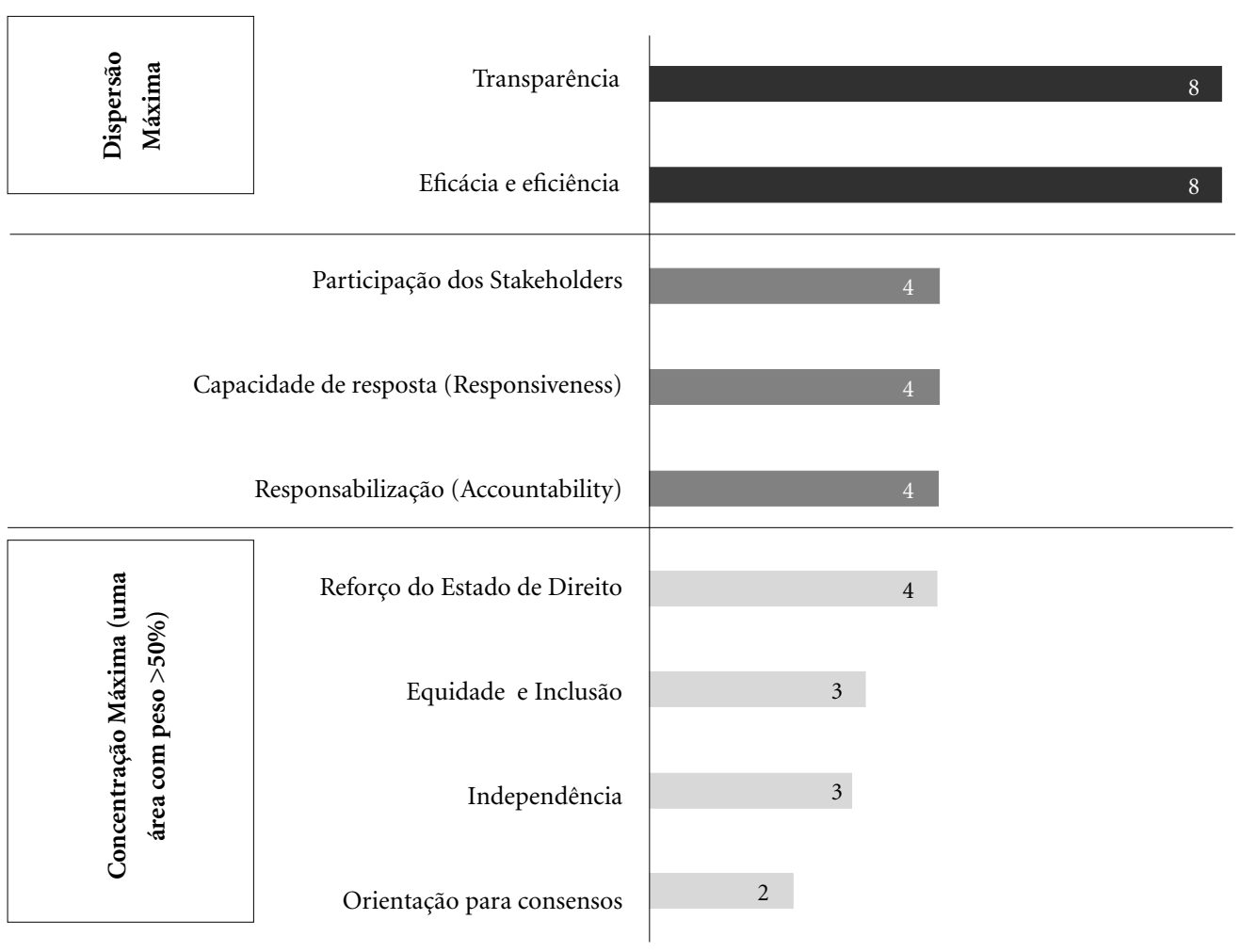

Gráfico 1. Número de áreas de intervenção em que se verifica a incidência de cada princípio de Boa Governança.

Fonte: Elaborado pelos autores.

mada decisão. Se no primeiro caso nos parece legítimo assumir que resulta, em boa parte, de uma imposição da Troika, muito presente nas medidas previstas no $M o U$, a preocupação com a "transparência” já, no nosso entender, deve ser atribuída a uma opção de atuação da equipa ministerial. A preocupação com a melhoria da "capacidade de resposta" do sistema de saúde, indo ao encontro das necessidades dos utentes, com a "responsabilização (accountability)" pelas decisões tomadas e com o contributo para o "reforço do Estado de direito" - criando condições para que exista na área da saúde um sistema legal justo e aplicado de forma efetiva e imparcial - são também observáveis, num segundo nível, na atuação do Ministério da Saúde. Com menor incidência, embora presentes, observam-se as preocupações com a "participação dos stakeholders" nos processos de decisão, com a "equidade" no acesso aos cuidados de saúde, com a garantia da "independência" dos gestores e com a criação de "consensos" em torno dos principais objetivos a definir e da forma de os atingir.

Ao analisar o quadro de associação entre as 50 medidas consideradas e os nove princípios de Boa Governança, segmentando pelas nove áreas de intervenção definidas, é possível perceber que a incidência dos princípios não é idêntica em todas as áreas, o que indicia preocupações diferenciadas por parte da equipa ministerial. Os princípios da "transparência" e da "eficácia/eficiência” estão presentes em oito das nove áreas de intervenção, demonstrando ser uma preocupação mais transversal. No outro extremo, encontram-se os que estão essencialmente associados a uma única área de intervenção, como é o caso da "orientação" para consensos", com uma incidência de $88 \%$ na área Acordos; da "independência", com uma incidência de 57\% na área Ética; do "reforço do Estado de Direito", com uma incidência de 56\% no Controlo; e da "equidade/inclusão", com uma incidência de 53\% no Cidadão no Centro do SNS. 




Gráfico 2. Identificação da área de intervenção predominante (peso superior a 50\%), nos princípios de Boa Governança onde esta existe.

Fonte: Elaborado pelos autores.

\section{Colaboradores}

R Ramos Pinto respondeu pelo enquadramento teórico da boa governança e análise da incidência dos princípios de boa governança. MH Monteiro fez a análise documental dos diplomas legais e outros documentos oficiais relativos às 50 iniciativas abordadas. MM Martins fez o desenho metodológico. ER Carvalho respondeu pelo enquadramento teórico.

\section{Agradecimento}

Os autores desejam agradecer todo o apoio prestado pelas entidades contactadas, sem o qual não teria sido possível ter acesso a toda a documentação que serve de suporte a este estudo.

\section{Financiamento}

Esta investigação foi suportada pela FCT - Fundação para a Ciência e a Tecnologia, através do projeto UID/CPO/00713/2019. 


\section{Referências}

1. Portugal, XIX Governo Constitucional. Tradução do conteúdo do Memorando de Entendimento sobre as Condicionalidades de Política Económica. Lisboa: Presidência do Conselho de Ministros; 2011[acessado 2018 Maio 2]. Available from: https://www.portugal. gov.pt/media/371372/mou_pt_20110517.pdf

2. Simões J. O Memorando de entendimento entre UE/ $B C E / F M I$ e Portugal. Intervenção na Conferência O Sector da Saúde. Como executar as medidas?. Lisboa: INA; 2001.

3. Bilhim J. Ciência da Administração. Lisboa: Instituto Superior de Ciências Sociais e Políticas; 2013.

4. Pollitt C, Hupe P. Talking about Government. Public Manage Rev 2011; 13(5):641-658.

5. Levi-Faur D. From 'Big-Government' to 'Big Governance'? In: Stephen PO, organizador. The New Pubic Governance? Emerging perspectives on the theory and practice of public governance. Londres: Routledge; 2012. p. 2-18.

6. Hughes O. Does Governance Exist? In: Stephen PO, organizador. The New Pubic Governance? Emerging perspectives on the theory and practice of public governance. Londres: Routledge; 2010. p. 87-104

7. Rhodes RAW. The New Governance: Governing Without Government. Polit Stud 1996; XLIV:652-667.

8. Pierre J. Governance and Institutional Flexibility. In: Levi-Faur D, organizador. Oxford Handbook of Governance. Oxford: Oxford University Press; 2012. p. 186-200.

9. Klijn EH. New Public Management and Governance: A Comparison. In: Stephen PO, organizador. The New Pubic Governance? Emerging perspectives on the theory and practice of public governance. Londres: Routledge; 2012. p. 201-214.

10. Bovaird T, Löffler E. Evaluating the quality of public governance: indicators, models and methodologies Int Rev Adm Sci 2003; 69(3):313-328.

11. Banco Mundial. Sub-Saharan Africa: From Crisis to Sustainable Growth. Washington D.C: World Bank; 1989.

12. Banco Mundial. Governance and Development. Washington D.C: World Bank; 1992. p. 1-3.

13. United Nations Development Programme (UNDP). Governance for Sustainable Human Development: A UNDP Policy Document. New York: UNDP; 1997.

14. United Nations Economic and Social Commission for Asia and the Pacific (UNESCAP). What is Good Governance? UNESCAP; 2009 [cited 2018 Maio 2]. Available from: http://www.unescap.org/sites/default/ files/good-governance.pdf

15. International Monetary Fund (IMF). Communiqué of the Interim Committee of the Board of Governors of the International Monetary Fund. Washington, D.C.: IMF; 1996. Available from: https://www.imf. org/external/np/sec/pr/1996/pr9649.htm

16. Comissão Europeia. European Governance: a white paper. Brussels: Commission of the European Comunities; 2001 [cited 2018 Maio 2]. Available from: http:// europa.eu/rapid/press-release_DOC-01-10_en.htm

17. OCDE. Glossary of Statistical Terms. Paris: OECD; 2007. [cited 2018 Maio 2]. Available from: https:// stats.oecd.org/glossary/download.asp
18. Banco Mundial. World Development Report 2017: Governance and the Law. Washington, DC: World Bank; 2017.

19. Williams, David e Young, Tom. Governance, the World Bank and Liberal Theory. Political Studies 1994; XLII:84-100.

20. British and Irish Ombudsman Association (Bioa). Guide to principles of good governance. [Internet]. Carshalton: British and Irish Ombudsman Association [cited 2018 Maio 2]. Available from: http://www. ombudsmanassociation.org/docs/BIOAGovernanceGuideOct09.pdf

21. Commission for Good Governance in Public Services (CIPFA). The Good Governance Standard for Public Services. London: Commission for Good Governance in Public Services; 2004 [cited 2018 Maio 2]. Available from: https://www.jrf.org.uk/sites/default/files/jrf/ migrated/files/1898531862.pdf

22. International Public Sector Governance Framework (IFAC). Good Governance in the Public Sector - Consultation Draft for an International Framework. New York: International Public Sector Governance Framework; 2013 [cited 2018 Maio 2]. Available from: http://www.ifac.org/system/files/publications/files/ Good-Governance-in-the-Public-Sector.pdf

23. Weiss TG. Governance, good governance and global governance: Conceptual and actual challenges. Third World Quarterly 2000; 21(5):795-814.

24. Hyden G, Court J. Governance and Development World Governance Survey Discussion Paper. New York United Nations University; 2002 [cited 2018 Maio 2] Available from: http://www.odi.org/sites/odi.org.uk/ files/odi-assets/publications-opinion-files/4094.pdf

25. Smith BC. Good Governance and Development. New York: Palgrave Macmillan; 2007.

26. World Health Organization (WHO). Governance for health in the $21^{\text {st }}$ century. Geneva: WHO; 2012 [cited 2018 Maio 2]. Available from: http://www.euro.who, int/_data/assets/pdf_file/0019/171334/RC62BD01Governance-for-Health-Web.pdf

27. Brand H. Good governance for the public's health. Eur J Public Health 2007; 17(6):541.

Artigo apresentado em 08/05/2018

Aprovado em 29/07/2019

Versão final apresentada em 31/07/2019

Editores-chefes: Romeu Gomes, Antônio Augusto Moura da Silva 
